\title{
Factors Influencing Uptake of IPTp3+ Among Pregnant Women Attending ANC in Mawokota North Health Sub District, Mpigi District, Uganda
}

\author{
Kizito Omona $[\mathrm{PhD}]^{1^{*}}$; Damali Mulungi ${ }^{1}$; Edson Twesigye ${ }^{1}$; Joram Tukamuhabwa ${ }^{1}$; \\ Medard Rukaari ${ }^{1}$; John Bosco Ninsiima ${ }^{1}$ \\ Faculty of Health Sciences, Uganda Martyrs University, Uganda \\ Corresponding Author: Dr Omona Kizito, Lecturer. E-mail: komona@umu.ac.ug, Tel: +256706464873 \\ DOI: 10.47760/cognizance.2021.v01i03.002
}

\begin{abstract}
Background: Annually, approximately 125 million pregnancies occur globally in malaria endemic areas. 25 million pregnant women are at risk for malaria which accounts for over 10,000 maternal and 200,000 neonatal deaths annually. WHO recommends initiation of IPT3+ in malaria endemic areas beginning with second trimester throughout pregnancy? However, uptakes of IPT3+ remain low in many countries, for instance in Uganda, the coverage of IPT3+ remains low at $66 \%$.
\end{abstract}

Objectives: The study objectives were; to determine the socio-demographic factors of women influencing uptake of IPTp3+, assess knowledge of women and facility related factors to offer IPTp3+,

Materials and Methods: Analytical cross sectional study design was used employing mixed methods. Quantitative data was collected using semi structured questionnaire among 150 women and qualitative data was collected from health workers as key informants. Quantitative data was analysed using SPSS v20 while coding and themes were used for qualitative data.

Results: Data was collected from 150 pregnant women. Study findings indicate that knowledge about group at high risk of getting Malaria $\left(\chi^{2}=4.113, d f=1, p=.043\right)$ and knowing how to use the drug $\left(\chi^{2}=6.590, d f=2, p=.037\right)$ was significantly associated with IPTP3+ Uptake of IPTp3+. The uptake of IPTp3+ was highest among pregnant women with correct knowledge about group at high risk of getting Malaria (46.7\%) and those who knew about the drug dosage (26.7\%). Findings further revealed that; the place Fansidar was picked from $\left(\chi^{2}=15.318, d f=4, p=.004\right)$ and staff availability to offer IPTP3+service $\left(\chi^{2}=10.956\right.$, $d f=2, p=.004)$ are the only facility related factors significantly associated with IPTP3+ Uptake. The uptake of IPTP3+ was highest amongst pregnant women who reported to have picked Fansidar from health facility (45.3\%) and reported availability of staff most of the times (42.7\%).

Conclusion: Knowledge about the group at risk of getting malaria, dosage of Fansidar, Availability of the drug stocks at the facility and staff availability significantly affected uptake of IPTP3+ by pregnant women in Mawokota North Health Sub District in Mpigi District.

Keywords: Intermittent Presumptive Treatment (IPT), Malaria, Pregnant Mothers, ANC 


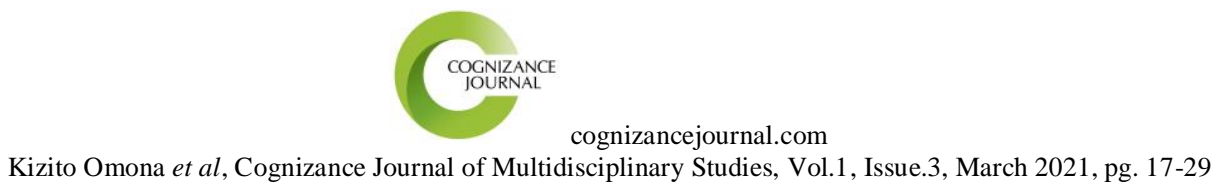

\section{INTRODUCTION}

Annually, approximately 125 million pregnancies occur globally in areas with Plasmodium falciparum and Plasmodium vivax transmission (1). Malaria in pregnancy (MiP) contributes to devastating maternal and neonatal outcomes, including maternal anaemia, maternal death, stillbirth, spontaneous abortion, and low birth weight with an estimated 10,000 women and 100,000 infants dying as a result of malaria in pregnancy (1) and therefore Malaria is a complex public health problem in African, where most cases and deaths are due to this disease (2).

Twenty-five million pregnant women are currently at risk for malaria, and, according to the World Health Organization. The impact is high in Sub Saharan Africa where women have high chances of getting parasitemia (3). According to the World health organization(WHO), In 2018, prevalence of exposure to malaria infection in pregnancy was highest in the West African sub region and Central Africa (each with 35\%), followed by East and Southern Africa (20\%). About $39 \%$ of these were in the Democratic Republic of the Congo and Nigeria(4)

Uganda is ranked fourth among the highest malaria-burden countries in the world with some of the highest transmission rates in the world; and pregnant women and children are particularly vulnerable because of their reduced immunity (3) and it's the leading cause of Morbidity and mortality (5). Malaria is a febrile illness that predisposes mothers poor pregnancy outcomes including severe or complicated malaria, abortion, premature labor, maternal anaemia among others(4) and the benefits of using IPT3+ prevent this have been documented (6).

To mitigate the consequences of Malaria in Pregnancy(MiP) in moderate to high malaria transmission areas, the World Health Organization (WHO) recommends that pregnant women receive intermittent preventive treatment during pregnancy (IPTp) with SP(7).SP is the drug of choice for preventing malaria in pregnancy in Uganda (WHO, 2018). Intermittent Preventive Treatment (IPT) decreases the incidence of low birth weight by $29 \%$, severe maternal anaemia by $38 \%$, and neonatal mortality by $31 \%$. (Roman et al 2019) IPTp is also one of the major public health interventions.

In 2012, the WHO released a policy that promotes the initiation of IPT3+ in areas of moderate to high malaria transmission, beginning as early as possible in the second trimester, at each scheduled antenatal care (ANC) (9). Since 2016, 36 African countries had adopted a 


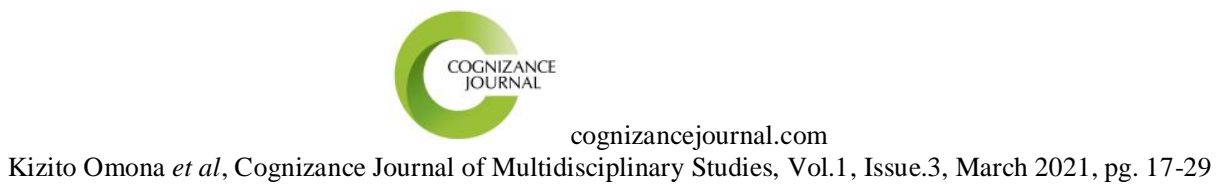

policy of providing IPTp3 to pregnant women. In 2016, the WHO estimated that coverage of IPTp1, 2, and 3 were 56\%, 43\%, and 19\%, respectively. The gap between high ANC attendance and the low proportion of eligible pregnant women receiving IPTp3 largely reflects a failure of the health system to provide IPTp-SP at ANC facilities (1).

Uganda has scaled up IPTp to tackle the challenge of Malaria in pregnancy in line with WHO recommendations. Sulfadoxine-pyrimethamine (SP) is the drug of choice for prevention of malaria during pregnancy given by Directly Observed Therapy (DOTs) system(10). There is slow uptake with $89 \%$ of women receiving one or more doses of SP, and this reduces to $45 \%$ of those who received two or more doses and further down to $25 \%$ who received three or more doses. (6).The coverage in Uganda has remained low with slight increase by only $4 \%$ to $66 \%$ from $63.2 \%$ in $2017 / 18$ (11)

Despite of several interventions put in place to prevent malaria in pregnancy, up take of IPTp3+ is still low hence the need for this study to establish factors affecting uptake of IPTp3+. According to the Okethwangu et al., 2019 awareness of benefits for taking SP in preventing malaria can influence it's uptake. However side effects have not been documented to affect it's uptake(12).

In a study done by(10) about Knowledge and utilization of intermittent preventive treatment for malaria among pregnant women about half $52.2 \%$ said that they have ever heard about IPTp, 23\% who had heard about IPTp were able to give a good definition of IPTp indicating low knowledge. Education level correlate with knowledge about IPT as $77 \%$ of pregnant women knowledgeable about IPT3 had primary and secondary level educationChukwurah et al., 2016,(14).

Facility staffing, availability of IPT 3 services affected IPT uptake. In Ghana 67\% of facilities lacked water for IPTp. Other factors reported like 56\% stock outs at facilities and inadequate supervision affected quality of service delivery. (2), (15) study revealed that there was lack of safe water and sharing cups during taking of DOTs was also a challenge.

Health workers being knowledgeable, and this only benefits the women who attained ANC (15). Findings from Ghana cost of services, distance to facility, Level of education, ANC schedule (16),(17).Distance to the health facility, pregnancy disclosure is among factors that affect ANC attendance and uptake of IPT3(9).

Elsewhere, in Malawi women reported obstacles were stock-outs of malaria test kits and treatment at health facilities and the distance to treatment (15.9\% and $15.0 \%$, respectively). 


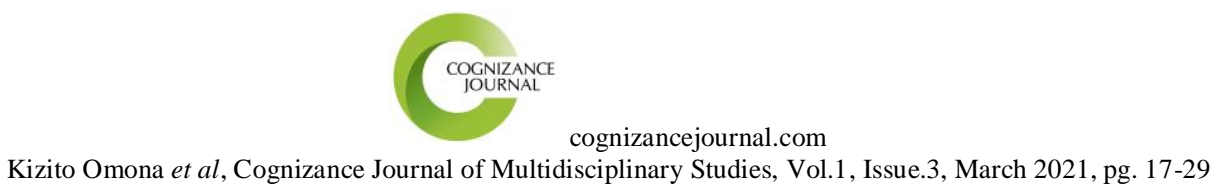

Similarly, Availability and accessibility of malaria prevention and medication influenced treatment uptake. This was mostly influenced by advice from healthcare staff and personal experiences $(12)$

There is scanty information on factors hindering uptake of IPTp3+ in Mpigi District. This study was done to asses factors affecting uptake of IPTp3+ Plus in in pregnant women with special focus on; knowledge of pregnant mothers on use of IPT3+; determine facility readiness to offer IPTp3+ and evaluate accessibility and availability of IPT3+ services in Mawokota North Health Sub District in Mpigi District

This study is timely because understanding such factors is paramount for designing strategies and programs for improving uptake and accessibility of IPT3+ services which will consequently result in reduction of malaria in pregnancy and its associated factors.

\section{OBJECTIVE}

\section{General Objective:}

To assess Factors influencing uptake of IPT3 Plus among pregnant women in Mawokota North Health Sub District, Mpigi District.

\section{Specific Objectives:}

1) To ascertain the level of uptake of IPTp3+ among pregnant mothers attending ANC in Mawokota North Health Sub-district, Mpigi district

2) To determine the Socio-demographic factors influencing the uptake of IPTp3+ in prevention of malaria in Mawokota North Health Sub District Mpigi District

3) To assess the knowledge of pregnant women on uptake of IPTp3+ in the prevention of malaria

4) To determine the association between knowledge factors and IPTp3+uptake among pregnant women attending ANC in Mawokota North Health Sub-District

5) To evaluate health facility related factors affecting uptake of IPTp3+ services in Mawokota North Health Sub District in Mpigi District

\section{MATERIALS AND METHODS}

Analytical cross sectional study design was used employing mixed methods. A sample of 150 pregnant women attending ANC was used. Quantitative data was collected using semi structured questionnaire. Qualitative data was collected from key informants using Key informant guide. The study area was Mawokota North Health Subdistrict (HSD), in Mpigi District. The district is in Central Uganda. 


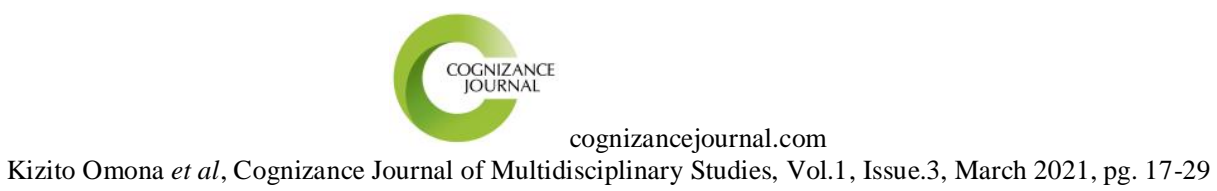

The study unit were Women attending ANC and eligible for IPTp3 and health workers providing ANC care in selected facilities in Mawokota North HSD as key informants. The sample size was calculated using Kish and Leslie formula (1965) and therefore, a total of 150 respondents were calculated.

The study used multi-stage random sampling to select the health sub district and facilities in the health district and systematic random sampling of women to participate in the study. Health workers were targeted as key informants at respective health facilities. The study used semi structured questionnaire and Key informant guide. Data analysis was done using SPSS v.20, and Qualitative data was analysed by Themes/content analysis. Cross Tabulation and Pearson Chi-Square was performed to establish the Association between variables and IPTp3+Uptake among pregnant Women. Data was analyzed descriptively, presented in tables and figures as appropriate and Cross Tabulation and Pearson Chi-Square was performed to establish the Association between Socio-Demographic Characteristics and IPTP3+ Uptake among pregnant Women.

A letter of introduction from the university faculty of Health Sciences, Uganda Martyrs University was taken to DHO, who endorsed it and introduced us to lower level facilities. Verbal consent was sought before any data collected.

\section{RESULTS}

\section{Socio-Demographic characteristics}

Majority of the respondents $41(27.3 \%)$ were in the age bracket of 21-24 with the least group $9(6.0 \%)$ being in the age bracket of 37 and above. Adolescents and young women constituted $46.6 \%$

\section{Uptake of IPTp3+ Among Pregnant Mothers Attending ANC}

IPTp3+Uptake among pregnant Mothers in Mawokota North Health Sub District, Mpigi district is shown in figure 1 below 
cognizancejournal.com

Kizito Omona et al, Cognizance Journal of Multidisciplinary Studies, Vol.1, Issue.3, March 2021, pg. 17-29

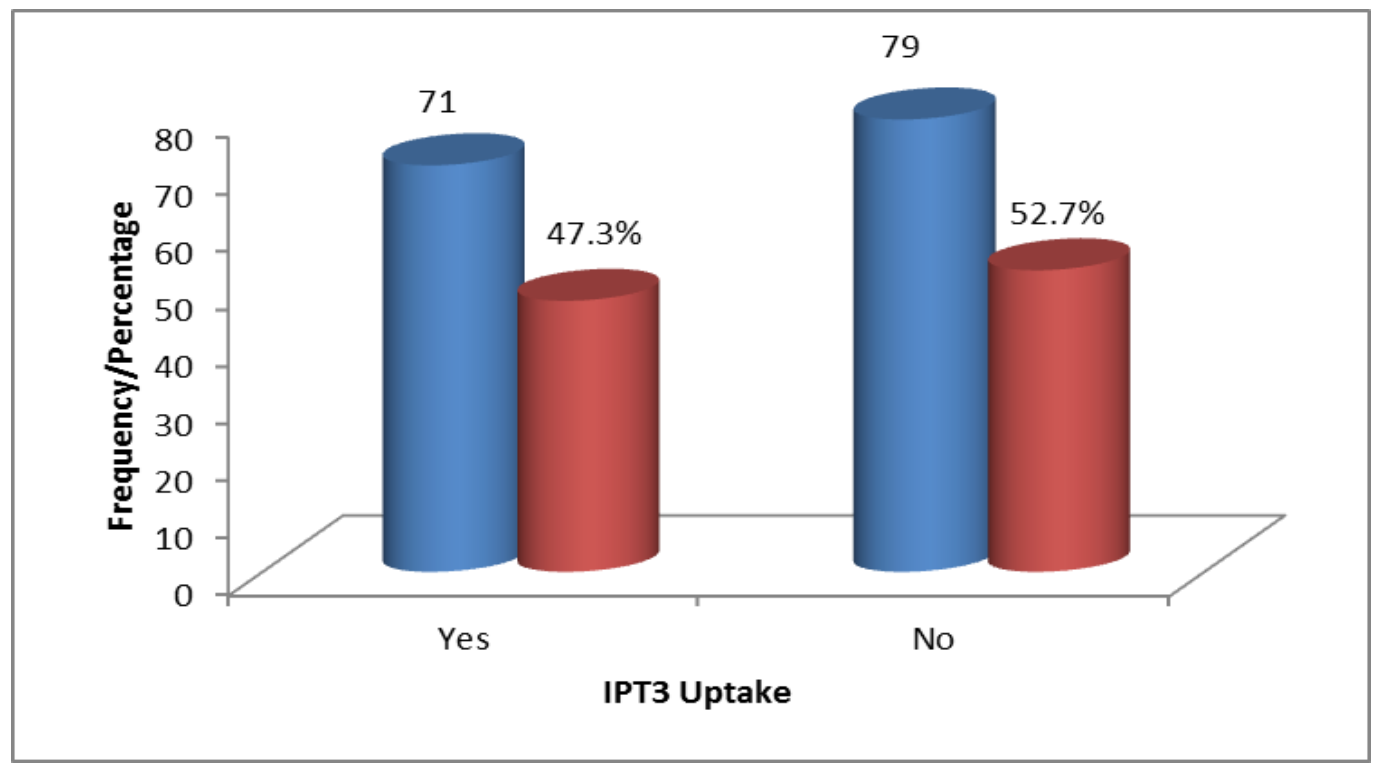

Figure 1: Uptake of IPTp3+ Among Pregnant Mothers

In the figure 1 above, the study found that among pregnant Mothers in Mawokota North Health Sub District, Mpigi district most of them that $52.7 \%$ by proportion did not make use of IPTp3+. The level of uptake of IPTp3+ was however as high as $47.5 \%$ among pregnant Mothers in Mawokota North Health Sub District.

Socio-demographic factors influencing the uptake of IPTp3+ in the prevention of malaria in Mawokota North Health Sub District District

Analysis of a number of socio-demographic factors was made. Cross Tabulation and Pearson Chi-Square results for association between Socio-demographic factors and IPTp3+ Uptake among Women was determined. See table 1 below

Table 1: Socio-demographic factors influencing the uptake of IPTp3+

\begin{tabular}{|c|c|c|c|c|}
\hline Socio-demographic Variables & & Uptake & Total & Test Statistics \\
\hline & Yes & No & & \\
\hline 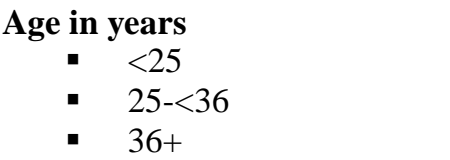 & $\begin{array}{l}33(22.0 \%) \\
31(20.7 \%) \\
7(4.7 \%)\end{array}$ & $\begin{array}{l}44(29.3 \%) \\
29(19.3 \%) \\
6(4.0 \%)\end{array}$ & $\begin{array}{l}77 \\
60 \\
13\end{array}$ & $\begin{array}{l}\chi^{2}=1.292 \\
\mathrm{df}=2 \\
p=0.524\end{array}$ \\
\hline $\begin{array}{cl}\text { Education Level } \\
\text { - } & \text { None } \\
\text { - } & \text { Primary } \\
\text { - } & \text { Secondary } \\
\text { - } & \text { Certificate } \\
\text { - } & \text { Diploma } \\
\text { - } & \text { Bachelors }\end{array}$ & $\begin{array}{l}4(2.7 \%) \\
28(18.7 \%) \\
35(23.3 \%) \\
3(2.0 \%) \\
0(0.0 \%) \\
1(0.7 \%)\end{array}$ & $\begin{array}{l}3(2.0 \%) \\
39(26.0 \%) \\
32(21.3 \%) \\
3(2.0 \%) \\
2(1.3 \%) \\
0(0.0 \%)\end{array}$ & $\begin{array}{l}7 \\
67 \\
67 \\
6 \\
2 \\
1\end{array}$ & $\begin{array}{l}\chi^{2}=4.670 \\
\mathrm{df}=5 \\
p=0.457\end{array}$ \\
\hline $\begin{array}{c}\text { Marital Status } \\
\text { - Single } \\
\text { - } \text { Married }\end{array}$ & $\begin{array}{l}12(8.0 \%) \\
54(36.0 \%)\end{array}$ & $\begin{array}{l}12(8.0 \%) \\
64(42.7 \%)\end{array}$ & $\begin{array}{l}24 \\
118\end{array}$ & $\begin{array}{l}\chi^{2}=1.091 \\
\mathrm{df}=3\end{array}$ \\
\hline
\end{tabular}


cognizancejournal.com

Kizito Omona et al, Cognizance Journal of Multidisciplinary Studies, Vol.1, Issue.3, March 2021, pg. 17-29

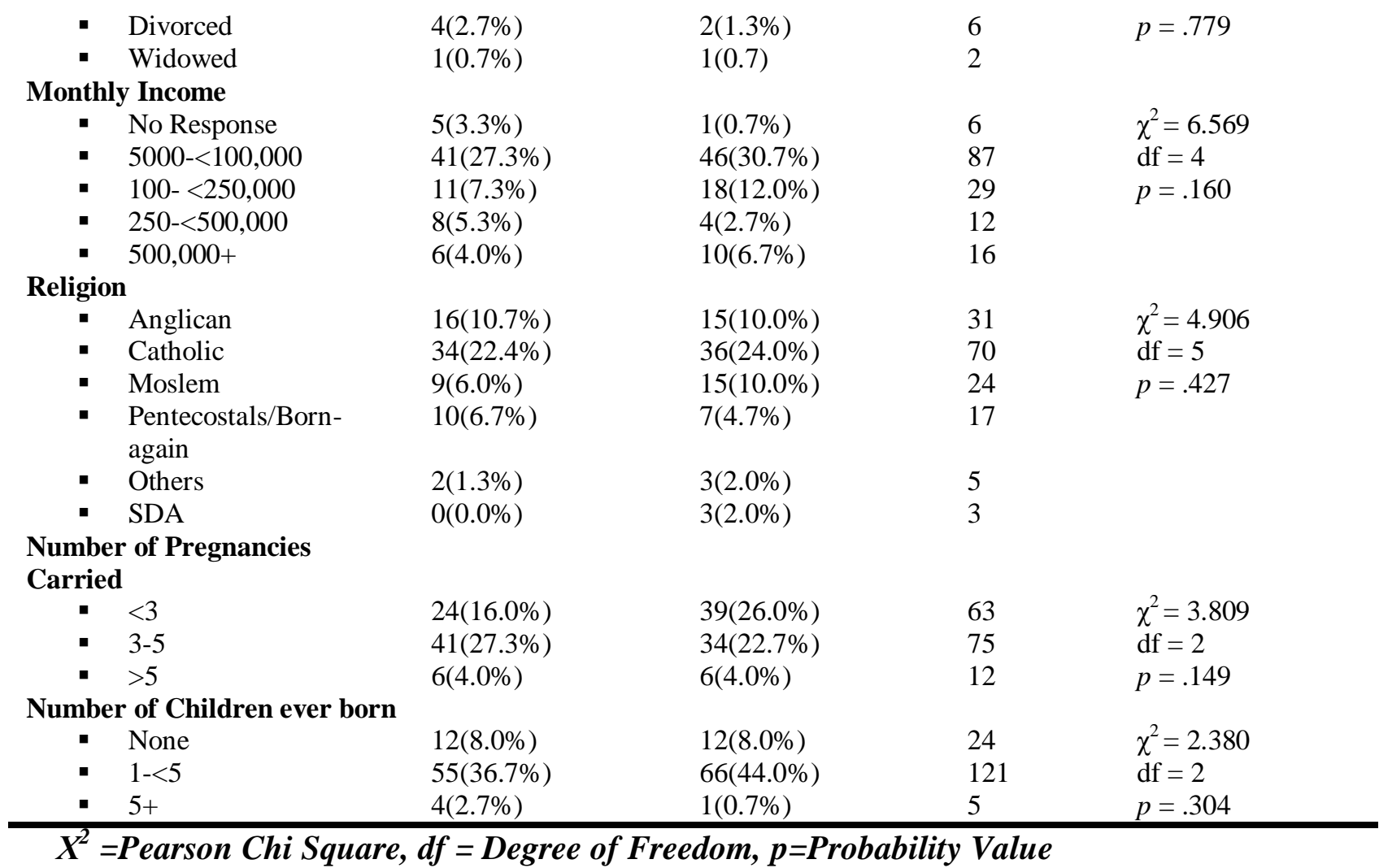

Table 1 show that none of the socio-demographic factors was significantly associated with IPTp3+ Uptake among pregnant women in Mawokota North Health Sub District. The study specifically found the age in years $\left(\chi^{2}=1.292, \mathrm{df}=2, \mathrm{p}=0.524\right)$, education Level $\left(\chi^{2}=4.670\right.$; $\mathrm{df}=5, \mathrm{p}=0.457)$, marital Status $\left(\chi^{2}=1.091, \mathrm{df}=3, \mathrm{p}=.779\right)$, monthly Income $\left(\chi^{2}=6.569, \mathrm{df}\right.$ $=4, \mathrm{p}=.160)$, religion $\left(\chi^{2}=4.906, \mathrm{df}=5, \mathrm{p}=.427\right)$, number of Pregnancies $\operatorname{Carried}\left(\chi^{2}=\right.$ $3.809, \mathrm{df}=2, \mathrm{p}=.149)$ and number of Children ever born $\left(\chi^{2}=2.380, \mathrm{df}=2, \mathrm{p}=.304\right)$ not significantly influencing uptake of IPTp3+ Uptake.

\section{Knowledge of Pregnant Women on Uptake of IPTp3+ in the Prevention of Malaria}

Mothers were asked questions related uptake of IPTp3+ in the prevention of malaria. The responses were the graded as 'Correct' or 'incorrect' as shown in table 2 below.

Table 2: Knowledge of Pregnant Women on Uptake of IPTp3+

\begin{tabular}{lll}
\hline Responses & Frequency & Percent \\
\hline Correct & 142 & 94.7 \\
Incorrect & 8 & 5.3 \\
Total & $\mathbf{1 5 0}$ & $\mathbf{1 0 0 . 0}$ \\
\hline
\end{tabular}

The table 2 above shows that majority of the respondents $142(94.7 \%)$ were aware of the groups of people at risk of being infected by malarial and the least $8(5.3 \%)$ were not aware. 


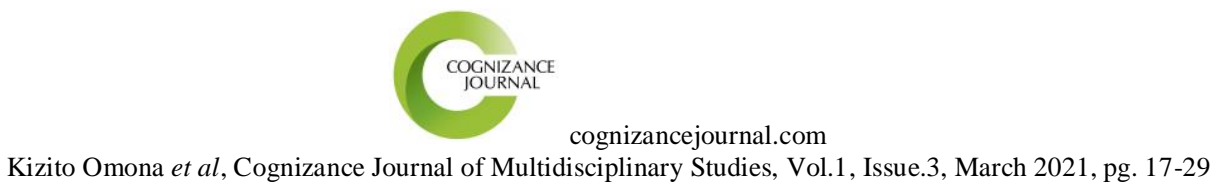

\section{Association Between Knowledge Factors and IPTp3+Uptake Among Women}

Cross Tabulation and Pearson Chi-Square for association between knowledge factors and IPTp3+Uptake among Women was determined. See results in table 3 below

Table 3: Association Between Knowledge Factors and IPTp3+Uptake Among Women

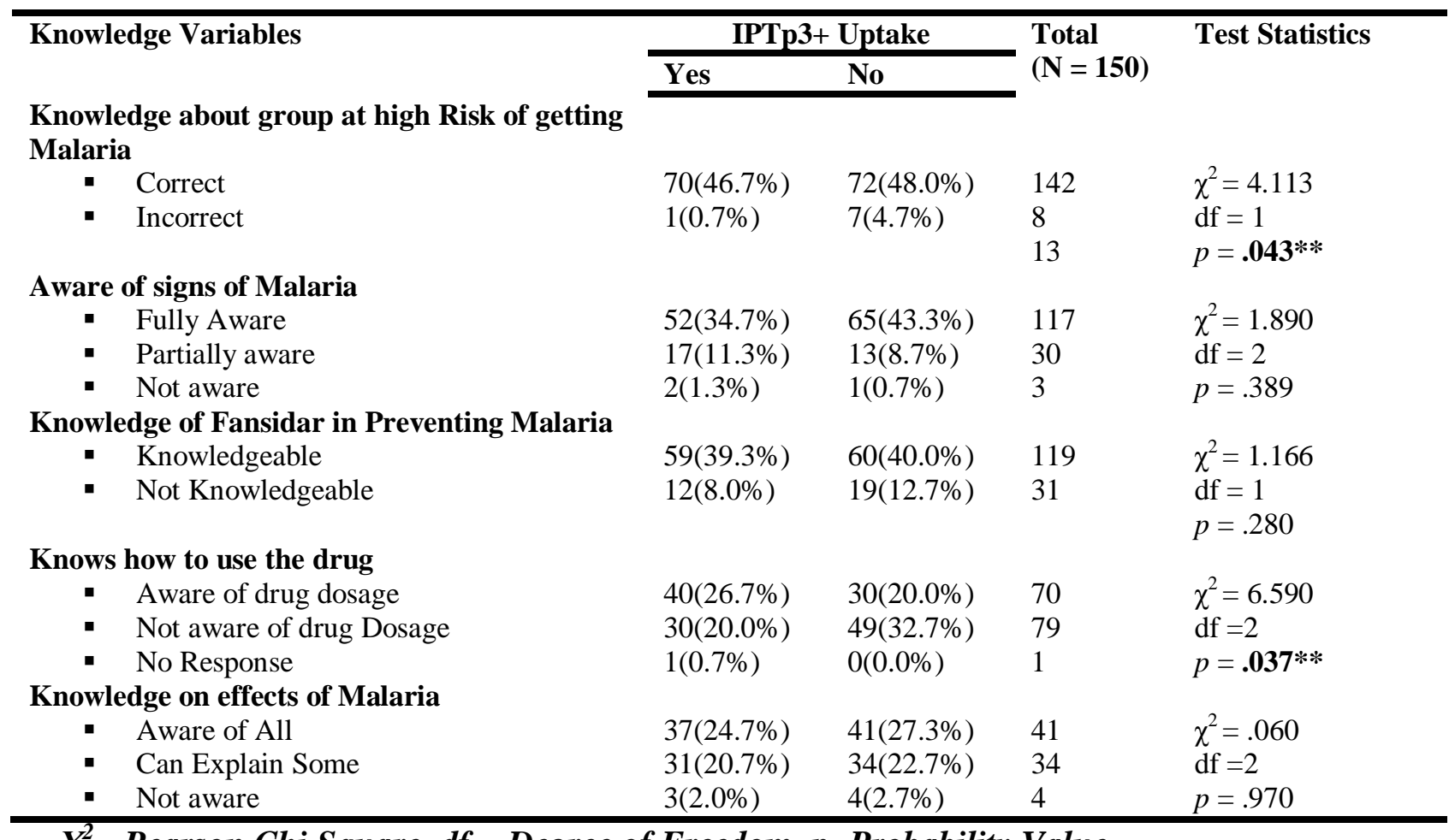

$X^{2}=$ Pearson Chi Square, $d f=$ Degree of Freedom, $p=$ Probability Value

The findings in relation to knowledge shows that aware of signs of malaria $\left(\chi^{2}=1.890, \mathrm{df}=2\right.$, $\mathrm{p}=.389)$, knowledge of fansidar in preventing malaria $\left(\chi^{2}=1.166, \mathrm{df}=1, \mathrm{p}=.280\right)$ and knowledge on effects of malaria $\left(\chi^{2}=.060, \mathrm{df}=2, \mathrm{p}=.970\right)$ had no significant association with IPTp3+ Uptake among pregnant women in Mawokota North Health Sub District.

The study results, however, show that knowledge about group at high risk of getting Malaria $\left(\chi^{2}=4.113, \mathrm{df}=1, \boldsymbol{p}=.043\right)$ and knowing how to use the drug $\left(\chi^{2}=6.590, \mathrm{df}=2, \boldsymbol{p}=. \mathbf{0 3 7}\right)$ was significantly associated with IPTp3+ Uptake among pregnant women in Mawokota North Health Sub District. The uptake of IPTp3+ was highest among pregnant women with correct knowledge about group at high risk of getting Malaria (46.7\%) and those who knew about the drug dosage $(26.7 \%)$.

\section{Facility Related Factors Affecting Uptake of IPTp3+ Services}

Most of the pregnant women $125(83.3 \%)$ received Fansidar from the facility, 12(5.3\%) received it from Private sector Clinics and only $1(0.7 \%)$ got it from the drug shop. However, $8.0 \%$ of the women did not receive fansidar since they were not eligible to start on IPTp. Majority of the respondents $57(38.0 \%)$ stay within a distance of $0-5 \mathrm{~km}$ and the least 25 $(16.7 \%)$ stay in a distance of $16 \mathrm{~km}$ and above. 
The facilities had an average of 5 staffs to offer the services, on average 4 staff had been trained, 2 of the facilities had guidelines to offer the services, 1 of the facilities had received a support supervision from the supervisory authorities and 1 facility had the required materials.

Table 4: Cross Tabulation and Pearson Chi-Square Results for Association between facility related factors and IPTp3+Uptake among pregnant Women

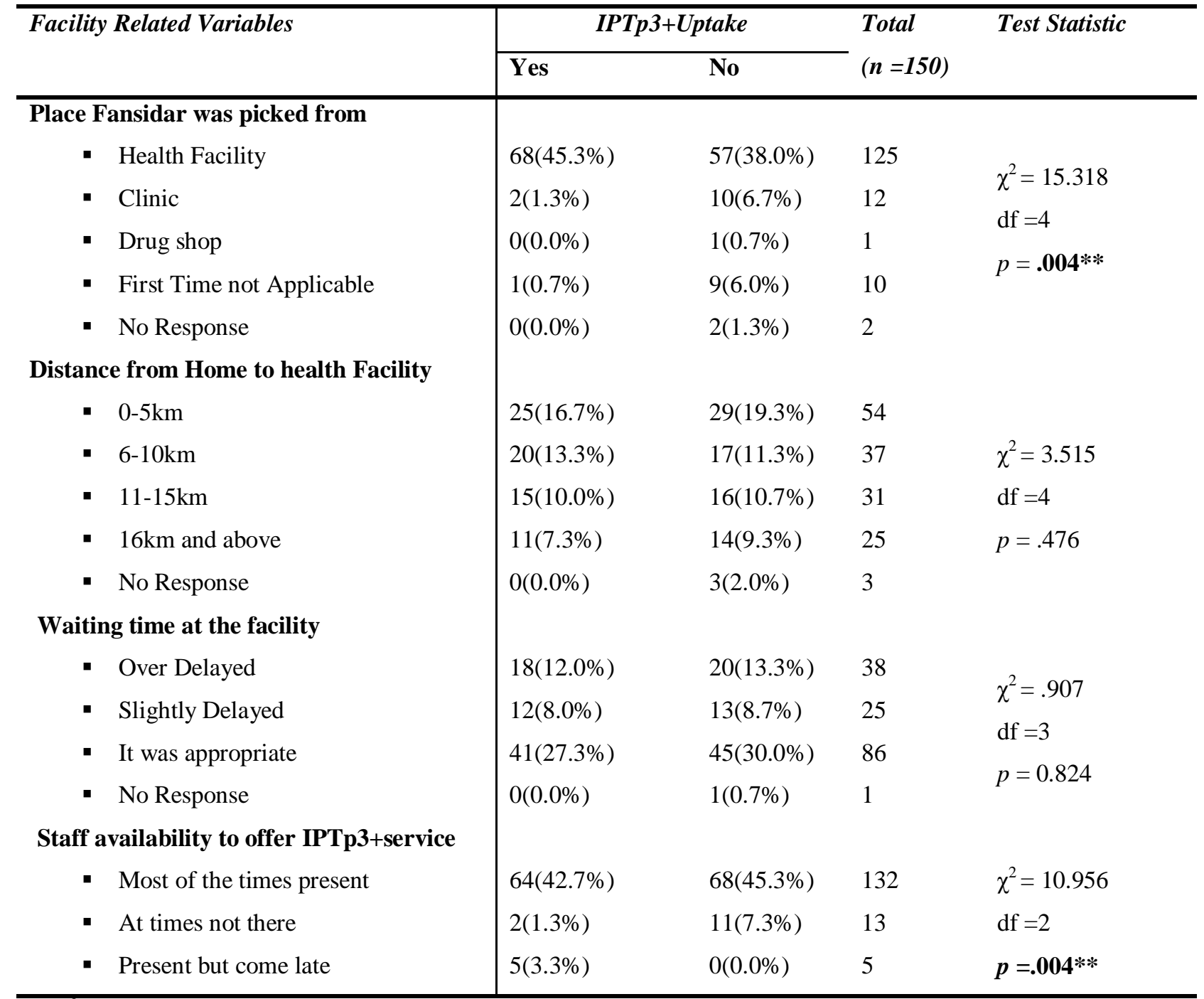

\section{$X^{2}=$ Pearson Chi Square, $d f=$ Degree of Freedom, $p=$ Probability Value}

Findings regarding facility related factors indicates that the distance from home to health facility $\left(\chi^{2}=3.515, \mathrm{df}=4, \mathrm{p}=.476\right)$ and waiting time at the facility $\left(\chi^{2}=.907, \mathrm{df}=3, \mathrm{p}=0.824\right)$ were not significantly associated with IPTp3+ Uptake among pregnant women in Mawokota North Health Sub District.

The results, however, show that the place Fansidar was picked from $\left(\chi^{2}=15.318\right.$, df $=4, \boldsymbol{p}$ $=.004)$ and staff availability to offer IPTp3+service $\left(\chi^{2}=10.956, \mathrm{df}=2, \boldsymbol{p}=.004\right)$ are the only facility related factors significantly associated with IPTp3+ Uptake among pregnant women in Mawokota North Health Sub District. The uptake of IPTp3+ was highest amongst pregnant 


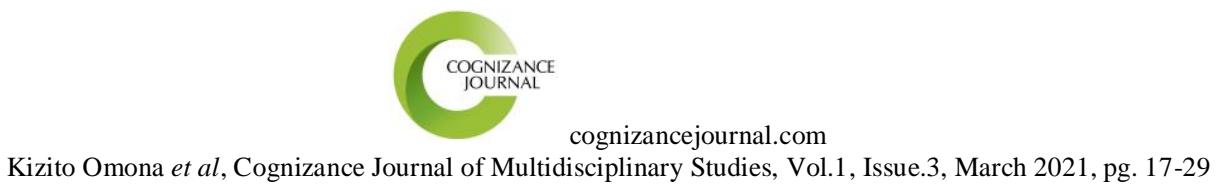

women who reported to have picked Fansidar from health facility (45.3\%) and reported availability of staff most of the times $(42.7 \%)$.

\section{DISCUSSION}

\section{Socio demographic factors affecting uptake of IPTp3+}

The current study found that none of the demographic characteristics that's age in years $\left(\chi^{2}=\right.$ 1.292, $\mathrm{df}=2, \mathrm{p}=0.524)$, education Level $\left(\chi^{2}=4.670 ; \mathrm{df}=5, \mathrm{p}=0.457\right)$, marital Status $\left(\chi^{2}=\right.$ $1.091, \mathrm{df}=3, \mathrm{p}=.779)$, monthly Income $\left(\chi^{2}=6.569, \mathrm{df}=4, \mathrm{p}=.160\right)$, religion $(\chi 2=4.906$, $\mathrm{df}=5, \mathrm{p}=0.427)$, number of Pregnancies Carried $\left(\chi^{2}=3.809, \mathrm{df}=2, \mathrm{p}=.149\right)$ and number of Children ever born $\left(\chi^{2}=2.380, \mathrm{df}=2, \mathrm{p}=.304\right)$ were influential in the uptake of IPTP3+ Uptake. Such a result is quite different from what was found Tanzania by Boateng and Anto (2017) that poverty among mothers greatly hinders the use of ANC services. The discrepancy in the current result could be attributed to variations of measurement as only monthly income was the only aspect considered in this study, yet poverty levels encompass several including assets.

\section{Knowledge factors and uptake of IPTp3+}

In this study it was established that knowledge in terms of awareness of signs of malaria $\left(\chi^{2}=\right.$ $1.890, \mathrm{df}=2, \mathrm{p}=.389)$, knowledge of fansidar in preventing malaria $\left(\chi^{2}=1.166, \mathrm{df}=1, \mathrm{p}\right.$ $=.280)$ and knowledge on effects of malaria $\left(\chi^{2}=.060, \mathrm{df}=2, \mathrm{p}=.970\right)$ did not significantly influence IPTp3+ Uptake among pregnant mothers. This result is different from those in a study which was done in Tanzania by (Mchwampaka et al., 2019) that mothers did not like taking Fansidar because of its associated side effects such as nausea. Such contradictions could be perhaps attributed to the fact that benefits of IPTp3+ exceed the side effects if well known by the pregnant mothers themselves.

This study however showed that knowledge about group at high risk of getting malaria $\left(\chi^{2}=\right.$ $4.113, \mathrm{df}=1, \mathrm{p}=.043)$ and knowing how to use the drug $\left(\chi^{2}=6.590, \mathrm{df}=2, \mathrm{p}=.037\right)$ had a significant influence on IPTp3+ Uptake among pregnant mothers. It was found that uptake was highest among pregnant mothers with correct knowledge about group at high risk of getting Malaria (46.7\%) and those who knew about the drug dosage $(26.7 \%)$. This result is consistent with what was found by Akinleye, Falade and Ajayi (2009) that little knowledge on the dosage of Fansidar was still a challenge and this greatly affects its usage. The result is also consistent with what was earlier established by Chukwurah et al. (2016) that knowledge enabled institution of possible preventive measures such the use of long lasting Insecticide treated nets (which found out that pregnant women were at high risk of acquiring the malaria. This could be attributed to fear of being infected as propelled by knowledge of the riskier groups. Besides knowing how to use integrates efforts easing uptake.

\section{Facility Related Factors and uptake of IPTp3+ among pregnant women.}

This study found the distance from home to health facility $\left(\chi^{2}=3.515, \mathrm{df}=4, \mathrm{p}=.476\right)$ and waiting time at the facility $\left(\chi^{2}=.907, \mathrm{df}=3, \mathrm{p}=0.824\right)$ were not significantly associated with IPTP3+ Uptake among pregnant mothers in Mawokota North Health Sub District. This finding is not similar to what was found in Malawi by Azizi, 2020) that distance to treatment 


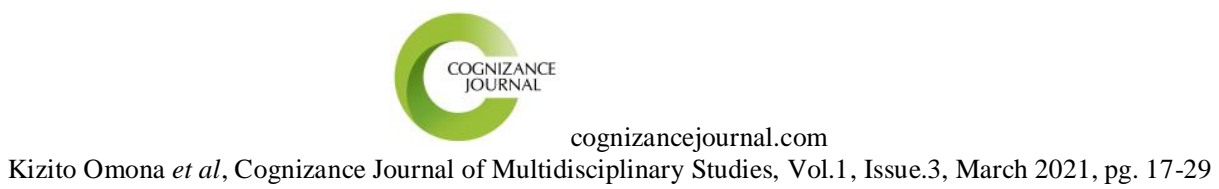

centers was a major obstacle for women is accessing health care and highlighted difficulties encountered when trying to access finances to be used to travel to the health care facilities.

The current study in addition found that public health facilities having the Fansidar $\left(\chi^{2}=\right.$ $15.318, \mathrm{df}=4, \mathrm{p}=.004)$ and staff being readily available to offer IPTp3+service $\left(\chi^{2}=10.956\right.$, $\mathrm{df}=2, \mathrm{p}=.004)$ significantly influenced with IPTp3+ Uptake among pregnant mothers. Such results are much similar to what was earlier found in a similar study done in Ghana which established that facilities were always stocked with IPT supplies and only experienced a stock out only ounce and that's even when the National medical Stores had caught fire. It was also revealed that staff availability and IPTp supplies helped pregnant women to receive all the prescribed drugs from the health facilities. In the same study staff confirmed that that they were always supplied in time with IPTp supplies (18).

\section{CONCLUSION AND RECOMMENDATIONS}

Study findings revealed that women's socio-Demographic characteristic was not significantly associated with uptake of IPTp3+. However, it revealed that Knowledge about the group at risk of getting malaria, dosage of Fansidar drug, Availability of the drug stocks at the facility ready to be dispensed to pregnant women and staff availability significantly affected uptake of IPTp3+.

\section{Recommendations:}

1. We recommend frequent health education sessions for all pregnant women on the importance of attending ANC and taking IPT during pregnancy with emphasis that pregnant women are at a risk of Malaria.

2. The health workers, community leaders should intensify mobilization and sensitization about the need for early ANC attendance, and the benefits of taking a complete SP dosage during pregnancy.

3. The government should increase the staffing levels at all health care facilities as a measure to improve uptake of IPT services.

4. Government and health Facilities should always maintain drug stocks and ensure that all pregnant women receive the prescribed drugs from the facility.

\section{ACKNOWLEDGEMENT}

The authors appreciate and acknowledge the support rendered by management Mpigi district health office towards the success of this study. We are indebted to our respondents without whom this study would not be possible

\section{DECLARATION}

The authors declare not conflict of interest. No external fund was got for this study 


\section{REFERENCES}

1. Roman E, Andrejko K, Wolf K, Henry M, Youll S, Florey L, et al. Determinants of uptake of intermittent preventive treatment during pregnancy: a review. Malar J [Internet]. 2019;1-9. Available from: https://doi.org/10.1186/s12936-019-3004-7.

2. Doku DT, Zankawah MM, Boateng A, Gyamfi A. Factors influencing dropout rate of intermittent preventive treatment of malaria during pregnancy. BMC Res Notes. 2016;1-7.

3. Okethwangu D, Opigo J, Atugonza S, Kizza CT, Nabatanzi M, Biribawa C, et al. Factors associated with uptake of optimal doses of intermittent preventive treatment for malaria among pregnant women in Uganda: analysis of data from the Uganda Demographic and Health Survey, 2016. Malar J [Internet]. 2019;1-8. Available from: https://doi.org/10.1186/s12936-019-2883-y.

4. Global Malaria Programme: WHO Global. World malaria report 2019 [Internet]. WHO Regional Office for Africa. 2019. Available from: https://www.who.int/newsroom/fact-sheets/detail/malaria.

5. Mbonye AK, Buregyeya E, Rutebemberwa E, Clarke SE, Lal S, Hansen KS, et al. Treatment and prevention of malaria in pregnancy in the private health sector in Uganda : implications for patient safety. Malar J. 2016;1-7.

6. Wanzira H, Katamba H, Okullo AE, Rubahika D. The challenge of using intermittent preventive therapy with sulfadoxine / pyrimethamine among pregnant women in Uganda. Malar J. 2016;1-7.

7. WHO. WHO policy brief for the Implementation of Intermittent Preventive Treatment of Malaria in Pregnancy Using Sulfadoxine-Pyrimethamine (IPTp-SP). WHO Press [Internet]. 2014;(October 2012):1-13. Available from: http://www.who.int/malaria/publications/atoz/iptp-sp-updated-policy-brief24jan2014.pdf?ua=1.

8. Experience P. Implementing Malaria in Pregnancy Programs in the Context of World Health Organization Recommendations on Antenatal Care for a Positive Pregnancy Experience. 2018;64(January):1-7.

9. Bajaria S, Festo C, Mrema S, Shabani J, Hertzmark E, Abdul R. Assessment of the impact of availability and readiness of malaria services on uptake of intermittent preventive treatment in pregnancy (IPTp) provided during ANC visits in Tanzania. Malar J [Internet]. 2019;18(1):1-10. Available from: https://doi.org/10.1186/s12936019-2862-3.

10. Akinleye SO, Falade CO, Ajayi IO. BMC Pregnancy and Childbirth Knowledge and utilization of intermittent preventive treatment for malaria among pregnant women attending antenatal clinics in primary health care centers in rural southwest, Nigeria : a cross-sectional study. 2009;9:1-9.

11. MOH Uganda. The Republic of Uganda Ministry of Health Annual Health Sector Performace Report 2016/17. Minist Heal Annu Heal Sect Perform Rep. 2019;1-147.

12. Pell C, Meñaca A, Afrah NA, Manda-Taylor L, Chatio S, Were F, et al. Prevention and management of malaria during pregnancy: Findings from a comparative qualitative study in Ghana, Kenya and Malawi. Malar J. 2013;12(1):1-13.

13. Chukwurah JN, Idowu ET, Adeneye AK, Aina OO, Agomo PU, Otubanjo AO. Knowledge , attitude and practice on malaria prevention and sulfadoxine pyrimethamine utilisation among pregnant women in Badagry, Lagos State, Nigeria. 2016;7(3):1-6. 
cognizancejournal.com

Kizito Omona et al, Cognizance Journal of Multidisciplinary Studies, Vol.1, Issue.3, March 2021, pg. 17-29

14. Sabin L, Hecht EMS, Brooks MI, Singh MP, Antwi KY, Rizal A, et al. Prevention and treatment of malaria in pregnancy: what do pregnant women and health care workers in East India know and do about it? Malar J [Internet]. 2018;1-13. Available from: https://doi.org/10.1186/s12936-018-2339-9.

15. Mchwampaka WM, Tarimo D, Chacky F, Mohamed A, Kishimba R, Samwel A. Factors affecting uptake of $\geq 3$ doses of Sulfadoxine-Pyrimethamine for malaria prevention in pregnancy in selected health facilities , Arusha region, Tanzania. 2019;0:1-8.

16. Boateng IO, Anto F. Intermittent preventive treatment of malaria in pregnancy : a cross - sectional survey to assess uptake of the new sulfadoxine - pyrimethamine five dose policy in Ghana. Malar J. 2017;1-9.

17. Portugaliza HP, Galatas B, Nhantumbo H, Djive H, Murato I, Saúte F, et al. Examining community perceptions of malaria to inform elimination efforts in Southern Mozambique: A qualitative study. Malar J [Internet]. 2019;18(1):1-14. Available from: https://doi.org/10.1186/s12936-019-2867-y.

18. Amankwah S, Anto F. Factors Associated with Uptake of Intermittent Preventive Treatment of Malaria in Pregnancy: A Cross-Sectional Study in Private Health Facilities in Tema Metropolis, Ghana. 2019;2019. 